\title{
THE EXPERIMENTAL RESEARCH OF PERCEPTION OF MODERN CHARACTERS IN A GROUP OF PRIMARY SCHOOL STUDENTS
}

\author{
Stanislava Turská ${ }^{1}$, Jana Kurotová ${ }^{2}$, Dominika Hoštáková ${ }^{3}$, Roman Chinoracký $^{4}$
}

\begin{abstract}
Nowadays we can run across various applications of modern technologies in all areas of social life. One of these applications is also an eye tracking technology that helps to answer questions related to human-computer interaction. Through the eye tracking technology we have tried to find out how primary school students perceive well-known comics characters with whom they come into contact through various information and communication technologies. Such a study is important in order to determine to which superhero characteristics children tend to be more inclined. Another reason why we decided to focus on this research is that there are currently no publications dealing with the issue. The main conclusion drawn from this research is the fact that primary school students are mainly interested in the positive characters of superheroes, but there are some other features that influence the perception of children, for example the colourful appearance of the character or the interesting equipment the character uses.
\end{abstract}

UDC Classification: 159.93, DOI: 10.12955/cbup.v7.1437

Keywords: Eye tracking, characters of superheroes, children psychology, key performance indicators, neuro marketing

\section{Introduction}

The present time is characterized by a significant expansion of information and communication technologies (Čorejová, 2015). Thanks to technological advances, a new virtual environment is being created and is hampering the 20th century paradigms. This environment affects all generations, with children and youth being the most sensitive group. The primary socialization of children is influenced by a number of factors, such as parents, siblings, friends, teachers and various other influences with which children come into contact. In the past, the most important socializing factors were mainly fairytale creatures such as princesses, brave knights, giants, dragons, fairies, watermen, witches and dwarfs. Nowadays, traditional fairy-tale creatures are in the process of being superseded by superhero characters from various comics and movies. Children encounter these characters through the Internet, to which they have access from various devices, such as a mobile phone, tablet or PC. However, when we compare the characters from the past with the characters of the present, we can say that the main idea remains the same because there is still a struggle of good with evil in a continuous conflict. Based on the aforementioned reasons in our research, we decided to focus on exploring how children, who are potentially most influenced at the time of their development (10 to 11 years old), perceive well-known characters of superheroes who represent various human traits and are represented in different appearances. We conducted research through one of the neuro-marketing methods, specifically through eye tracking technology.

\section{Literature review}

Every person is able to see almost $100 \%$ of the information which can be found in the world around them. There are many methods and ways in the world which we can detect the interaction between a person and the world, which can perceive with eyes. From the perspective of neuroscience, the best and most appropriate method is the eye tracking method, which is able to track the interconnection that arises between a person and the outside world (Madleňák, 2018).

\section{History of eye tracking method}

Wade and Tatler (2009) describe that in 1800 the first reference to eye tracking appeared in science. If we compare eye tracking in the present and in the past, we can say that even though the technology at that time was not as advanced as it is now, people were able to perform studies in which they focused on tracking the movements of eyes. The first person who developed the most important studies about eye tracking was Alfred Lukyanovich Yarbus. This Russian psychologist was involved in many studies

\footnotetext{
${ }^{1}$ Department of Communications, The Faculty of Operation and Economics of Transport and Communications, University of Žilina, Žilina, Slovak Republic, stanislava.turska@fpedas.uniza.sk

${ }^{2}$ Department of Communications, The Faculty of Operation and Economics of Transport and Communications, University of Žilina, Žilina, Slovak Republic, jana.kurotova@fpedas.uniza.sk

${ }^{3}$ Department of Communications, The Faculty of Operation and Economics of Transport and Communications, University of Žilina, Žilina, Slovak Republic, dominika.hostakova @fpedas.uniza.sk

${ }^{4}$ Department of Communications, The Faculty of Operation and Economics of Transport and Communications, University of Žilina, Žilina, Slovak Republic, roman.chinoracky @ fpedas.uniza.sk
} 
using the eye tracking method. In his studies, he pointed to the existing relationship between a steady eye view and the observation of an interesting subject (Martinez-Conde and Macknik, 2015). Since 1800 there has been a steady increase in the number of studies on eye tracking. The years 1900-1950 can be described as ground-breaking because at that time researchers have been largely involved in researching how people read. In the 1980s, researchers experimented on the hypothesis that focused on the eye mind. The research confirmed their hypothesis which resulted in the person spending the same time thinking and looking at the object at which he was looking at the moment (Embretson, 1998). Over the years, the method was questioned and refuted. Scientists argued that there are certain factors that made it impossible for a person to concentrate $100 \%$ on a particular object because of the ineffectiveness of the factors. In 1980, eye tracking was first used to track the relationship between a person and a computer. The research was aimed at monitoring the human eye response to the command windows. The command windows were shown to test participants when the participant was working with the computer. These researchers also made advancements in the technology by using real time eye tracking results to help disabled people.

\section{Types of eye tracking devices}

We distinguish two types of eye tracker devices: remote (also called screen-based or desktop) and headmounted (also called mobile). Remote eye trackers record eye movement at a distance. There is no attachment of such device to the tested participant. It is mounted under or placed near to a computer or screen and the participant - respondent is seated in front of eye tracker. It is recommended to use this type of eye tracker in laboratory settings for observations of any screen-based stimulus material such as offline stimuli (books, magazines, etc.), pictures, videos, websites and other similarly small settings (small shelf studies etc.). Another type of eye tracker are head-mounted devices. They record eye activity from a close range. Such eye tracker devices are mounted onto light-weight eyeglass and the participant is able to walk around freely with this device. This equipment is recommended for observations of objects and task performance in any real-life or virtual environments - usability studies, product testing, testing in real environment and so on (Madleňák, 2016). Our research was realized through the remote eye tracking device.

\section{Definition of eye tracking}

The issue of eye tracking is being dealt with in a number of publications of many different authors. Duchowski (2007) and Hudák (2017) describe eye tracking as a method which offers a unique measure of human attentional behaviour. Traditional methods of measurements of human performance often include measures of reaction time and accuracy. For example: how fast a person completes a task and how well this task is performed. Such measurements are often associated with performance. Duchowski adds that the analysis of the performed individual procedures is needed in order to study the steps taken to perform the tasks. For this analysis, the measurements of the processes is needed. Eye movements are particularly interesting in this latter context because they present measures that can provide insights into the visual, cognitive, and attentional aspects of human performance. Authors Majaranta and Bulling (2014) in their work analysed eye-based human-computer interaction. According to these authors eye tracking can be defined as a way of tracking eye movements or a process of monitoring movements of eyes or the total point of gaze which refers to the point of the user's gaze which is focusing at the visual output. Eye tracking is applicable in various areas, for example in psychology, medical diagnostic, usability studies, or interactive and gaze-controlled applications. Singh and Singh (2012) define eye tracking as the monitoring process of eye movements and the determination of where the user is looking. There are different principles used in measuring eye movements. For example measurements of electric and photoelectric signals, monitoring a number of viewable features in the vision of the eye, measuring the relative reflection of infrared light, and using either mechanical or optical levers or a magnetic field.

In the field of neuroscience, most eye tracking studies have focused on transport (Hudák, 2016; Madleňák 2016), medicine and marketing (Madleňák, 2016; Hudák 2017). Within the analysis of available resources, we did not find any publications dealing with research into child psychology through eye tracking technology. This was the main reason and the motivation why we decided to conduct our experimental research on how modern superhero characters are perceived by primary school students. 


\section{Methodology}

The main goal of the research was to identify how the characters of new heroes are perceived in the age group of children who attend primary school. With regard to the dominance of visual perception, experimental eye-camera testing was used as a research method. Specifically, it was the REDn Scientific model from the company SMI. It is a reliable screen-based eye tracker that enables researchers to conduct fixation based studies with a sampling rate of $30 \mathrm{or} 60 \mathrm{~Hz}$. The testing was carried out in the HMI-LAB (Human-Machine Interaction Laboratory) located in the premises of the University Science Park of University of Zilina. The object of research was a group of 18 children aged $10-11$ years, 10 boys and 8 girls. The subjects of research were selected superhero characters from the production of Marvel and DC Comics (see Figure 1).

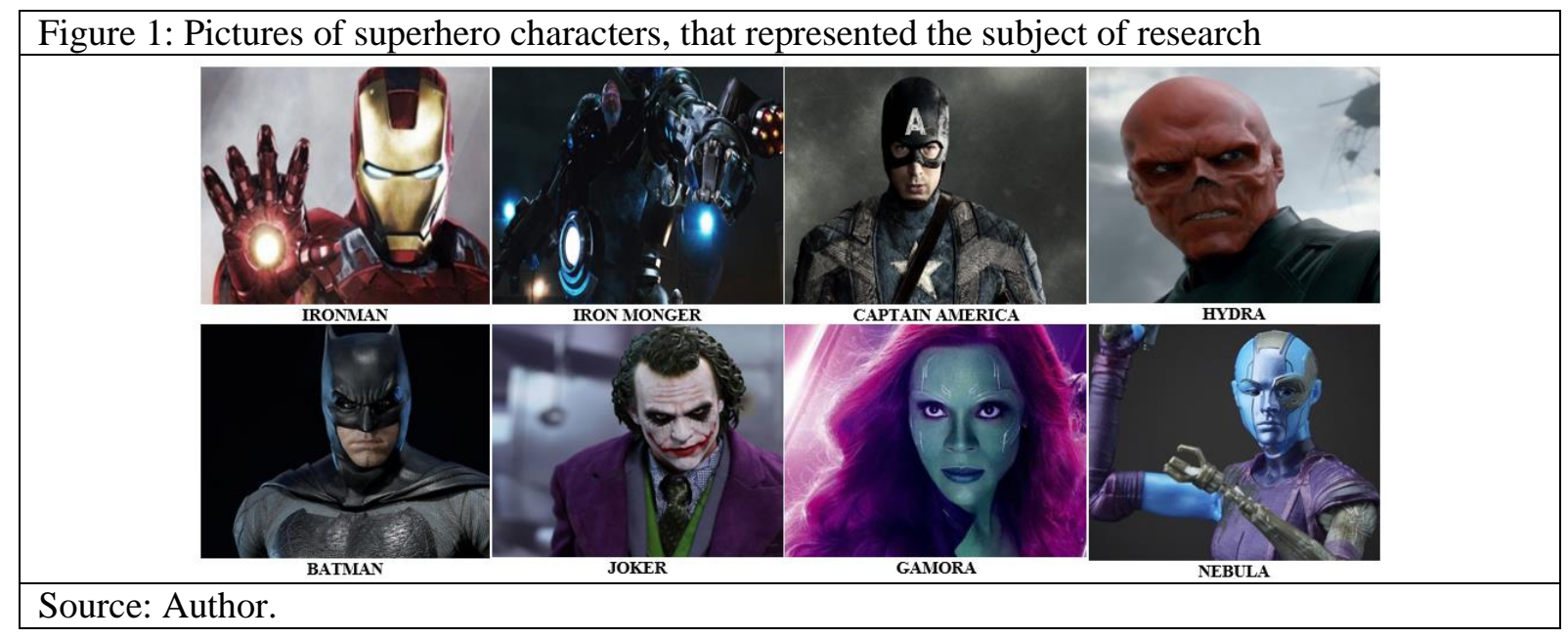

We prepared and implemented the experiment using the software SMI Experiment Suite Scientific. As part of the experiment preparation, we have always selected two incentives (images of two superheroes, one with positive and the other with negative characteristics) who in the framework of testing formed the so-called areas of interest. The Area of Interest (AOI) is a tool to select regions of a displayed stimulus, and to extract metrics specifically for those regions. AOI defines the area (zone of interest) by which other metrics are calculated. They might be defined either before the experiment or after it, during the analysis process. Subsequently, we exposed them for 5 seconds to each tester. We then evaluated the results of the measurement with the eye camera in the SMI BeGaze software. To express the degree of interest in the appropriate stimulus, we chose the following metrics:

- Entry Time is the average duration from start of the trial test to the first gaze view of an AOI.

- Dwell Time represents the time spent looking within the defined area of interest. It is sum of all fixations and saccades within an AOI for all selectedparticipants (testers).

- Revisitors count the number of participants (testers) with more than one visit in an AOI.

\section{Results}

The research we carried out focused on the perception of positive and negative superheroes through neuroscience. Through the research we wanted to find out how the individual respondents perceive the heroes and what most interests them with the hero.

\begin{tabular}{|l|c|c|c|c|c|c|c|c|c|}
\hline Table 1: Comparison of selected KPI between positive and negative superheroes \\
\hline \multirow{3}{*}{ Character } & \multicolumn{3}{|c|}{ Entry time (ms) } & \multicolumn{3}{c|}{ Dwell time (ms) } & \multicolumn{3}{c|}{ Revisitors } \\
\cline { 2 - 12 } & Boys & Girls & All & Boys & Girls & All & Boys & Girls & All \\
\hline Iron Man & 273.8 & 101.9 & 197.4 & 1893.1 & 2583.1 & 2199.8 & 8.0 & 7.0 & 15.0 \\
\hline Iron Monger & 483.8 & 531.1 & 504.8 & 2366.4 & 1941.5 & 2177.5 & 5.0 & 4.0 & 9.0 \\
\hline Captain America & 483.7 & 241.7 & 376.1 & 2853.1 & 3137.2 & 2979.3 & 6.0 & 4.0 & 10.0 \\
\hline Hydra & 251.1 & 1162.5 & 209.4 & 1553.2 & 1474.8 & 1518.3 & 5.0 & 4.0 & 9.0 \\
\hline Joker & 363.7 & 135.7 & 262.4 & 2303.1 & 1695.7 & 2033.1 & 8.0 & 5.0 & 13.0 \\
\hline Batman & 147.1 & 356.5 & 240.2 & 2199.8 & 2891.4 & 2507.2 & 10.0 & 5.0 & 15.0 \\
\hline Gamora & 672.7 & 224.3 & 451.7 & 1973.2 & 2170.7 & 2060.9 & 8.0 & 6.0 & 14.0 \\
\hline Nebula & 150.6 & 191.0 & 169.9 & 2099.8 & 2312.3 & 2194.2 & 7.0 & 7.0 & 14.0 \\
\hline Source: Author & \multicolumn{10}{|c|}{} \\
\hline
\end{tabular}




\section{Iron Man vs Iron Monger}

The first pair of superheroes that appeared to the respondents on the screen was a pair of superheroes Iron Man and Iron Monger. On the left side of the screen was a positive superhero - Iron Man and a negative superhero - Iron Monger was on the right side of the screen. The characters shown in the pictures come from the Iron Man movie published by Marvel Comics.

The Iron Man character is more vivid compared to the Iron Monger character. The dominant colours in the case of Iron Man are gold and red. The Red colour evokes a strong emotional charge and stimulates life energy, while the gold colour symbolizes justice, courage and cordiality. The image of Iron Monger is shown in dark colours. Dark colours generally create a sense of fear, evil and, on the other hand strength, endurance, and justice.

The indicator hit ratio was in this case $100 \%$, so we can say that, every respondent saw the picture of each superhero. When the picture of Iron Man appeared, the first time the girls in average were looking at this picture for $101.9 \mathrm{~ms}$. Subsequently, they moved their view to negative superhero Iron Monger. The entry time for Iron Monger was for girls $531.1 \mathrm{~ms}$. Boys took a longer time to look at the positive superhero Iron Man. Their entry time was $273.8 \mathrm{~ms}$, while the transition to a negative hero was less than that of the girls and was measured with a time of $483.8 \mathrm{~ms}$. When we look at the average entry time for all respondents, their entry time was $197.4 \mathrm{~ms}$ at the positive superhero Iron Man and at the negative superhero Iron Monger the entry time was $504.8 \mathrm{~ms}$.

As far as the dwell time indicator is concerned, for girls it took in average $2583.1 \mathrm{~ms}$ to look at a picture of the positive superhero Iron Man. Girls were looking at the picture of Iron Monger about one fifth of a time less than at the picture of Iron Man. On the contrary, the boys in overall were looking at the picture of Iron Man 1893.1 ms and at the picture of Iron Monger they were looking $2366.4 \mathrm{~ms}$. From the point of view of the average for the whole group of respondents, respondents spent almost the same time viewing both positive and negative superheroes.

For each group of respondents the indicator of revisits - 1.3 - was the same for the picture of Iron Monger. Same applies for the picture of Iron Man, where there was 0.9 revisits. The indicator of revisitors showed different results for each group of respondents. In the picture of Iron Man, up to 8 out of 10 boys returned to the picture, while 7 out of 8 girls returned to the picture. In the picture of Iron Monger from each group of respondents exactly half of the boys and girls returned to the picture.

The first fixation of girls at the picture of the positive superhero Iron Man was almost $100 \mathrm{~ms}$ longer than the first fixation of boys at the same picture. At the picture of Iron Monger, the first fixation of girls was also higher than the first fixation of boys. The measured value of first fixation for girls was $160 \mathrm{~ms}$ longer than the first fixation of boys. Average first fixation of all respondents was higher at the picture of Iron Man - 309.2 ms than at the picture of Iron Monger which was on average $294.4 \mathrm{~ms}$.

At first, all respondents spent a longer time looking at the image of a negative superhero Iron Monger, but the overall viewing time was longer for the image of the positive hero Iron Man. The boys were more interested in the negative superhero Iron Monger on which they spent almost the same time as the girls spent looking at the positive superhero Iron Man. At the same time, we can say that the pictures were more attractive to girls than to boys, because the white space around the pictures was observed only in a group of boys.

\section{Captain America vs Hydra}

The second pair was Captain America, who represented a group of positive superheroes and Hydra, who represented a group of negative superheroes. As in the previous picture, a positive superhero was placed on the left side and a negative superhero was on the right side. These characters had main roles in the movies Captain America and the Avengers. These movies were created by Marvel Comics. The dominant feature of Captain America is a black mask and a colourful shield that, especially in small children, gives a sense of knightly courage. The second character represents an ugly person with a damaged face, red in colour, who makes obnoxious feelings.

In the case of the positive character, the measurement was successful at $100 \%$. In the group of boys there was observed a $90 \%$ success of measurement of the negative character. The measurement error occurred either because of the inattention of one of the boys, the shortness of time, or the lack of interest in the character. 
The entry time indicator told us, that the girls looked at first at Captain America, where their value was $241.70 \mathrm{~ms}$. There stayed on the picture a long time, because the entry time in Hydra was measured as $1,162.50 \mathrm{~ms}$. On the other hand, the boys viewed first the picture of the negative hero, where their measured value was $251.10 \mathrm{~ms}$ and then they moved to the picture of the positive superhero, where their time was $483.70 \mathrm{~ms}$. The average for all respondents was $376.10 \mathrm{~ms}$ with Captain America, and for Hydra it was $209.40 \mathrm{~ms}$. They looked at the picture of Hydra as the first picture and then moved to the image of Captain America.

The dwell time of the boys was on the picture of Captain America was 2,853.10 ms and the girls had a dwell time of 3,137.2 ms. In terms of the average, all respondents viewed this picture 2,979.3 ms. In the picture of Hydra, the dwell time of was boys less than 1,300 ms while girls had a value less than $1 / 2$ of that time, which they spent on a positive superhero. The average time spent on the negative hero was $1518.30 \mathrm{~ms}$. Based on the results, we can say that the respondents spent less time on the Hydra picture than on the positive superhero picture.

In the picture of the positive superhero Captain America boys had a first fixation less than $400 \mathrm{~ms}$ over the girls. Hydra was dominated by boys because their first fixation was measured at $360 \mathrm{~ms}$, where the girls had their value at $245.80 \mathrm{~ms}$. In terms of the overall average of respondents, the indicator was larger in the Captain America picture at $453.70 \mathrm{~ms}$. Hydra had an indicator of $309.20 \mathrm{~ms}$, which is about 150 ms less compared to Captain America.

The revisits indicator was measured in Captain America's picture at 0.70 for boys and 1.0 for girls. In average, the indicator was 0.83 after rounding for this picture. The picture of Hydra had revisits of boys 0.80 , girls 1.0 and the average for all respondents was 0.89 after rounding The revisitors indicator showed us that Captain America and Hydra returned more boys than girls. Captain America returned 6 out of 10 boys while only 4 out of 8 girls. On the other hand Hydra returned 5 out of 9 boys ( 1 respondent didn't see the picture), and again only 4 girls out of 8 girls. In terms of the average, more than half of the respondents returned to the picture of Captain America while Hydra returned exactly half.

Based on the results, we can say that the girls are more attracted by the positive hero, which was mainly reflected in the fixation of the superhero. The boys were interested in the negative superhero Hydra. Even in this preview, we saw a white space indicator that found that 1 out of 8 respondents, representing $12.5 \%$, looked at the area outside the pictures.

\section{Joker vs Batman}

In the next measurement, each respondent had the same time to view a picture which consisted of two parts. On the left side was placed a negative character and on the right side was placed a positive superhero. The negative picture was Joker from DC Comics who was the main enemy of the positive superhero Batman. The characteristic feature of Joker is a smiling face that is caused by paralysis of his facial nerve. The picture of the Joker dominates with a purple colour in jacket which a symbol of magic, mysticism and spirituality in the context of colour psychology. The philosophy of the Joker character is the theory by which he believed that every human being is in some way spoiled in his inner being and hiding his true self from everyday mischief. The character of the Joker is a mad psychopath, and therefore in this measurement an example of a negative picture. The character of Batman is one of the most famous superheroes. A distinctive feature of Batman is his black bat which is generally associated with fear, sadness and some degree of mystery. In general, Batman is a law protector who tries to protect innocents.

The entry time indicator of first viewing was higher of $22.20 \mathrm{~ms}$ in the picture of the Joker than in the picture of the Batman in both groups of respondents. When comparing entry time, the negative character was attractive mainly to boys who spent $363.70 \mathrm{~ms}$ watching the Joker while girls watched more the positive character whose entry time was $356.50 \mathrm{~ms}$.

However, if we compare the dwell time of both groups, respondents spent a higher time looking at the positive picture, where the difference was $474.10 \mathrm{~ms}$. In comparison of boys and girls individually, we can say that the boys spent more time looking at the negative picture while the girls were focused on the picture of Batman.

The success of measurement of both objects was $100 \%$, as all respondents noticed the positive and negative character. When we compared revisitors, we found out that respondents looked back several times to the positive character while this indicator was the same in both cases of positive and negative 
pictures in the group of girls. Under the first fixation, we found out that the highest fixation was for girls with Batman, which was up to $920.80 \mathrm{~ms}$. In the aggregate assessment of a given indicator, the value of the first fixation was higher for the positive character, where the total difference between the positive and the negative character was $42.60 \mathrm{~ms}$.

In the end of the analysis of all indicators we can say that the respondents were focused at first gaze on the positive picture. We can conclude that the Joker became a subject of interest in the group of boys while the Batman charmed the girls. We can also say that both characters were sufficiently interesting for the respondents because there was no white space measurements.

\section{Gamora vs Nebula}

The last eye tracking measurement was focused on a pair of pictures from Guardians of the Galaxy. The picture consists of two different superhero characters where the positive character was Gamora and the negative character was Nebula. The typical feature of Gamora is her green colour of the skin and distinctive dark hair with purple highlights. The green colour generally stimulates a neutral impression but green skin colour can be associated with the symbolism of an extra-terrestrial civilization. Gamora is a pretty young woman who has gone through a catharsis within a story where a cold and hard woman gradually becomes a very caring and loving creature. The adoptive sister of Gamora was Nebula which represents the symbol of evil. The characteristic features are not generally dark colours, however purple is the dominant colour. In general these colours are symbols for a certain form of spirituality and mystery. When we compare both of these characters, Gamora has a much more intriguing and more interesting impression.

When we look at the dwell time indicator we can see that the total time spent by respondents looking at the object was higher for Nebula. The revisits indicator tells us that the boys have returned their views to a particular location in both pictures of characters more times compared to the girls. When comparing characters according to the index of revisitors, we can say that the respondents returned the view of the character Gamora and Nebula in the same number. The boys have repeatedly returned to Gamora and the girls to Nebula.

Through the first fixation we found out that the highest fixation was in the case of Nebula in the group of girls. This highest fixation represented a value of $337.50 \mathrm{~ms}$. The lowest fixation value was in the group of boys while watching the same picture of Nebula. From this indicator we can state that the girls spent more time looking at the negative character at first and while the boys looked at the positive character. The value of the first fixation was higher in the case of the positive character where the overall difference between the positive and the negative character was $22.30 \mathrm{~ms}$. However, the success of the measurements of the Gamora and Nebula pictures was not higher than previous measurements. The hit rate indicator was $94.40 \%$ and indicates less inattention from one respondent.

When we summarized the values of all indicators, we can state that the boys were particularly interested in Nebula who showed an example of a negative character and similarly the girls were also attracted by the negative character Nebula. However, when we assess which of the characters have attracted respondents at first glance we must say that it was the positive character which could have been caused by the fact that the Gamora character is significantly more colourful and brighter than Nebula. At the same time, we can say that pictures were more attractive to boys than to girls, because the white space was observed only in the group of girls.

\section{Conclusion}

In general we can conclude that eye tracking is a form of research that monitors eye movement, in particular where people look and why they look there. This means that there are many areas where eye tracking can be used. Performance measures typically quantify how a person performed (e.g., with what speed and accuracy), however, process measures cannot only corroborate performance gains, but can also lead to discoveries of reasons for performance improvements. In particular, tracking the users' eyes can potentially lead to further insights into the underlying human cognitive processes under varying conditions and workloads.

The eye tracking research, used in the field of neuroscience, focused on the perception of well-known characters from the DC and Marvel Comics in the group of primary school students aged ten to eleven. Based on the research, we found out that the respondents were interested in the positive characters in the majority of cases. Through the dwell time parameter, which expresses the time spent by the 
respondents looking at the object, we found out that the respondents had a bigger interest in the positive character of Iron Man, Captain America and Batman in 3 of 4 measurements. This could be caused by several reasons. Among the most significant reasons we can include the colourful appearance of the superheroes, the state of knowledge of superheroes in children, the equipment of superheroes, and the beauty and the nice outer appearance of the superheroes. In the last measurement the negative hero came out as the most eye-catching. Such a result can be caused by the fact that the Nebula character is a very prominent object in the field of cyborg with a futuristic appearance, which is very engaging, interesting and significant for children today. Based on the white space parameter, we can say that the error rate was higher in the group of girls. In terms of positive superheroes, the hero Captain America was the most attractive among all respondents. Otherwise, Nebula came out as the most engaging negative superhero.

With this research, we have shown that children in primary socialization tend to be more positive about the character traits of superheroes. We recommend further research that could focus on identifying specific character traits / features that can most likely affect children in the next stages of life.

\section{Acknowledgement}

This paper was developed under the support of project: VEGA 1/0721/18 the research of economic impacts of visual smog on transport using methods of neuroscience.

\section{References}

Corejova, T., Al Kassiri, M. (2015) The Power of Knowledge-Intensive Services. In: 4th International Conference on Social Sciences and Society (ICSSS 2015), Pt 1 Location: Paris, FRANCE Date: MAY 20-21, 2015 , Book Series: Advances in Education Research, Volume: 70 Pages: 354-357 Published: 2015

Duchowski, A. (2007). Eyetracking methodology Theory and Practice. pp. 51. ISBN 978-1-84628-608-7.

Embretson, S. E.: A cognitive design system approach to generating valid tests: Application to abstract reasoning. Psychological Methods, 1998, 3(3), 380-396. doi:10.1037/1082-989x.3.3.380

Hudak, M., \& Madlenak, R. (2016). The research of driver's gaze at the traffic signs. CBU International Conference Proceedings 2016: Innovations in Science and Education (pp. 896-899).

Hudak, M., \& Madlenak, R. (2017). The Research of Driver Distraction by Visual Smog on Selected Road Stretch in Slovakia. Proceedings of the 16th International Scientific Conference Reliability and Statistics in Transportation and Communication (Vol. 178, pp. 472-479). Amsterdam: Elsevier Science Bv.

Hudak, M., Madlenak, R., \& Brezaniova, V. (2017). The impact of advertisement on consumer's perception. CBU International Conference Proceedings 2017: Innovations in Science and Education (Vol. 5, pp. 187-191). Prague 8: Central Bohemia Univ.

Madlenak, R., Hostakova, D., Madlenakova, L., Drozdziel, P., \& Torok, A. (2018). The analysis of the traffic signs visibility during night driving. Advances in Science and Technology-Research Journal, 12(2), 71-76. doi:10.12913/22998624/92103

Madlenak, R., \& Hudak, M. (2016). The Research of Visual Pollution of Road Infrastructure in Slovakia. Challenge of Transport Telematics, TST 2016 (Vol. 640, pp. 415-425). Cham: Springer Int Publishing Ag.

Madlenak, R., Hudak, M. (2016). Analysis of Roadside Advertisements on Selected Road Stretch in Zilina. Proceedings of the 20th International Scientific Conference Transport Means 2016 (pp. 618-621). Kaunas: Kaunas Univ Technology Press. Madlenak, R., \& Kianickova, E. (2016). Advertising emails optimisation by eytracking technology. Marketing Identity: Brands We Love, Pt I (pp. 186-194). Trnava: Univ Ss Cyril \& Methodius Trnava-Ucm Trnava.

Majaranta, P., \& Bulling, A. (2014). Eye Tracking and Eye-Based Human-Computer Interaction. Springer-Verlag London. Retrieved from https://perceptual.mpi-inf.mpg.de/files/2014/07/majaranta14_apc.pdf

Martinez-Conde, S., Macknik, S. L.: From Exploration to Fixation: An Integrative View of Yarbus's Vision. Perception, 2015, 44(8-9), pp. 884-899. doi:10.1177/0301006615594963

Jarasuniene, A., Yatskiv, I.: Analysis of improvement of road safety using intelligent transport systems (ITS). TRANSPORT MEANS 2007, Proceedings, Kaunas, Kaunas Universi-ty of Technology, pp.182-185, 2007.

Singh, R., \& Singh, J. (2012). Human Eye Tracking and Related Issues: A Review. International Journal of Scientific and Research Publications, Volume 2, Issue 9. ISSN 2250-3153. Retrieved from http://www.ijsrp.org/research-paper-0912/ijsrpp0929.pdf

Stalmasekova, N., Genzorova, T., Corejova, T. et al. (2017) The Impact of Using the Digital Environment in Transport. In: Conference: 12th Int. Scient. Conf. Of Young Scientists on Sustainable, Modern and Safe Transport. Location: High Tatras, Slovakia. Date: May 31-June 02, 2017. Book series: Procedia Engineering. Volume: 192, Pages 231-236, 2017

Torok, A.: Comparative analysis between the theories of road transport and emission. Transport 32(2), 192-197 (2017)

Wade, N. J., Tatler, B. W.: Did Javal measure eye movements during reading? Journal of Eye Movement Research, 2009, 2(5), p. 7.

Was, Ch., \& Sansosti, F., \& Morris, B. (2017). Eye-Tracking Technology Applications in Educational Research. ISSN: 2327-3275. eISSN: 2327-3283. Retrieved from https://ccl.northwestern.edu/2017/Shayan.Abrahamson.Bakker.Duijzer.vdSchaaf.2017.eye-tracking-chapter-Global.pdf 